\title{
Pre-operative Obesity-Associated Hyperandrogenemia in Women and Hypogonadism in Men Have No Impact on Weight Loss Following Bariatric Surgery
}

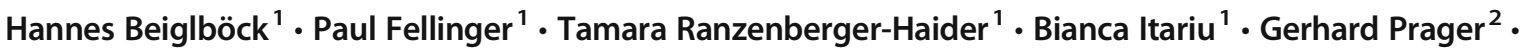 \\ Alexandra Kautzky-Willer ${ }^{1} \cdot$ Michael Krebs $^{1}$ (D) $\cdot$ Peter Wolf $^{1}$
}

Received: 29 January 2020 / Revised: 01 June 2020 / Accepted: 04 June 2020 / Published online: 13 June 2020

(C) The Author(s) 2020

\begin{abstract}
Background In severe obesity, hypogonadism in men and androgen excess in women are frequently observed. Sex hormones play an important role in body composition and glucose and lipid metabolism. However, whether pre-operative gonadal dysfunction impacts weight loss after bariatric surgery is not fully known.

Methods A total of 49 men and 104 women were included in a retrospective analysis. Anthropometric characteristics, glucose and lipid metabolism, and androgen concentrations were assessed pre-operatively and $17.9 \pm 11$ or $19.3 \pm 12$ months postoperatively in men and women. Men with $\left(\mathrm{HYPO}_{\text {male }}\right)$ and without (controls: $\mathrm{CON}_{\text {male) }}$ pre-operative hypogonadism, as well as women with $\left(\mathrm{HYPER}_{\text {female }}\right.$ ) and without (controls: $\mathrm{CON}_{\text {female) }}$ pre-operative hyperandrogenemia, were compared.

Results In men, pre-operative hypogonadism was present in $55 \%$ and linked to a higher body mass index (BMI): $\mathrm{HYPO}_{\text {male }} 50 \pm$ $6 \mathrm{~kg} / \mathrm{m}^{2}$ vs. $\mathrm{CON}_{\text {male }} 44 \pm 5 \mathrm{~kg} / \mathrm{m}^{2}, p=0.001$. Bariatric surgery results in comparable changes in $\mathrm{BMI}$ in $\mathrm{HYPO}_{\text {male }}$ and $\mathrm{CON}_{\text {male }}$ $-16 \pm 6 \mathrm{~kg} / \mathrm{m}^{2}$ vs. $-14 \pm 5 \mathrm{~kg} / \mathrm{m}^{2}, p=0.30$. Weight loss reversed hypogonadism in $93 \%$. In women, androgen excess was present in $22 \%$, independent of pre-operative BMI: $\mathrm{CON}_{\text {female }} 44 \pm 7 \mathrm{~kg} / \mathrm{m}^{2}$ vs. HYPER female $45 \pm 7 \mathrm{~kg} / \mathrm{m}^{2}, p=0.57$. Changes in BMI were comparable in HYPER female and $\mathrm{CON}_{\text {female }}$ after bariatric surgery $-15 \pm 6 \mathrm{~kg} / \mathrm{m}^{2} \mathrm{vs} .-15 \pm 5 \mathrm{~kg} / \mathrm{m}^{2}, p=0.88$. Hyperandrogenemia was reversed in $61 \%$.

Conclusions Besides being frequently observed, hypogonadism in men and androgen excess in women have no impact on postsurgical improvements in body weight and glucose and lipid metabolism. Weight loss resulted in reversal of hypogonadism in almost all men and of hyperandrogenemia in the majority of women.
\end{abstract}

Keywords Androgen excess · Testosterone deficiency · Functional hypogonadism

Michael Krebs

michael.krebs@meduniwien.ac.at

Hannes Beiglböck

hannes.beiglboeck@meduniwien.ac.at

Paul Fellinger

paul.fellinger@meduniwien.ac.at

Tamara Ranzenberger-Haider

tamara.ranzenberger-haider@meduniwien.ac.at

Bianca Itariu

bianca.itariu@meduniwien.ac.at

Gerhard Prager

gerhard.prager@meduniwien.ac.at
Alexandra Kautzky-Willer

alexandra.kautzky-willer@meduniwien.ac.at

Peter Wolf

peter.wolf@meduniwien.ac.at

1 Division of Endocrinology and Metabolism, Department of Internal Medicine III, Medical University of Vienna, Währinger Gürtel 18-20, 1090 Vienna, Austria

2 Division of Bariatric Surgery, Department of General Surgery, Medical University of Vienna, Währinger Gürtel 18-20, 1090 Vienna, Austria 


\section{Introduction}

Bariatric surgery is an effective treatment option for morbid obesity. Besides favorable effects on body weight, it was shown that cardiovascular risk factors like type 2 diabetes mellitus, hypertension, dyslipidemia, and non-alcoholic fatty liver disease improve following surgery $[1,2]$, resulting in decreased all-cause mortality [3].

Sex hormones are well known to play an important role in body composition and glucose and lipid metabolism, of which especially androgens are characterized by a sexual dimorphism $[4,5]$. In men with hypogonadism, reduced testosterone concentrations are associated with obesity, insulin resistance, and hypertension [6], resulting in increased cardiovascular mortality [7]. Hypogonadism is frequently observed in men with morbid obesity and improves following bariatric surgery [8-10]. Since testosterone deficiency is associated with abdominal obesity and testosterone replacement therapy promotes muscle strength and physical activity, pre-operative hypogonadism might have adverse effects on long-term post-operative improvement in cardiovascular risk factors [11, 12].

In contrast to the favorable impact of testosterone in men, women with hyperandrogenemia are often obese and more likely to have metabolic syndrome. The most common cause of androgen excess in women is polycystic ovary syndrome (PCOS), which is closely linked to insulin resistance and obesity and has an unfavorable influence on women's quality of life [13-16]. Alterations in sex hormone-binding globulin (SHBG) synthesis in the liver, which is mainly influenced by body fat and insulin, provide one possible mechanism for the increased testosterone levels observed in women with morbid obesity [5, 17, 18]. SHBG binds testosterone with high affinity. Decreased concentrations of SHBG in obesity thus result in a greater percentage of free testosterone and a condition of relative functional hyperandrogenemia [18]. Bariatric surgery might be a promising therapy to improve symptoms as well as insulin sensitivity and hypertension in women with obesity and PCOS [19].

Testosterone plays an important role in the development of metabolic diseases and cardiovascular risk factors in a sexspecific manner. Therefore, this study aims to analyze longterm weight loss and improvements in cardiometabolic risk factors depending on pre-operative androgen hormone status in men and women.

\section{Patients and Methods}

The medical records of all patients in routine care at the obesity outpatients' clinic of the Medical University of Vienna, Department of Medicine III, Division of Endocrinology and
Metabolism, from January 2015 to September 2019 were analyzed retrospectively.

The study protocol was approved by the ethics committee of the Medical University of Vienna. The inclusion criteria for men and women were history of bariatric surgery for morbid obesity, availability of anthropometric data, and laboratory parameters including androgen concentrations preoperatively and post-operatively. In total, 49 men and 104 women met these criteria and were included in analysis (see Fig. 1). The mean follow-up period was $17.9 \pm 10.9$ months for men and $19.3 \pm 11.5$ months for women. The anthropometric data including height, weight, and body mass index (BMI) were analyzed pre-operatively and at the last followup at the obesity outpatients' clinic (Figs. 2 and 3). The

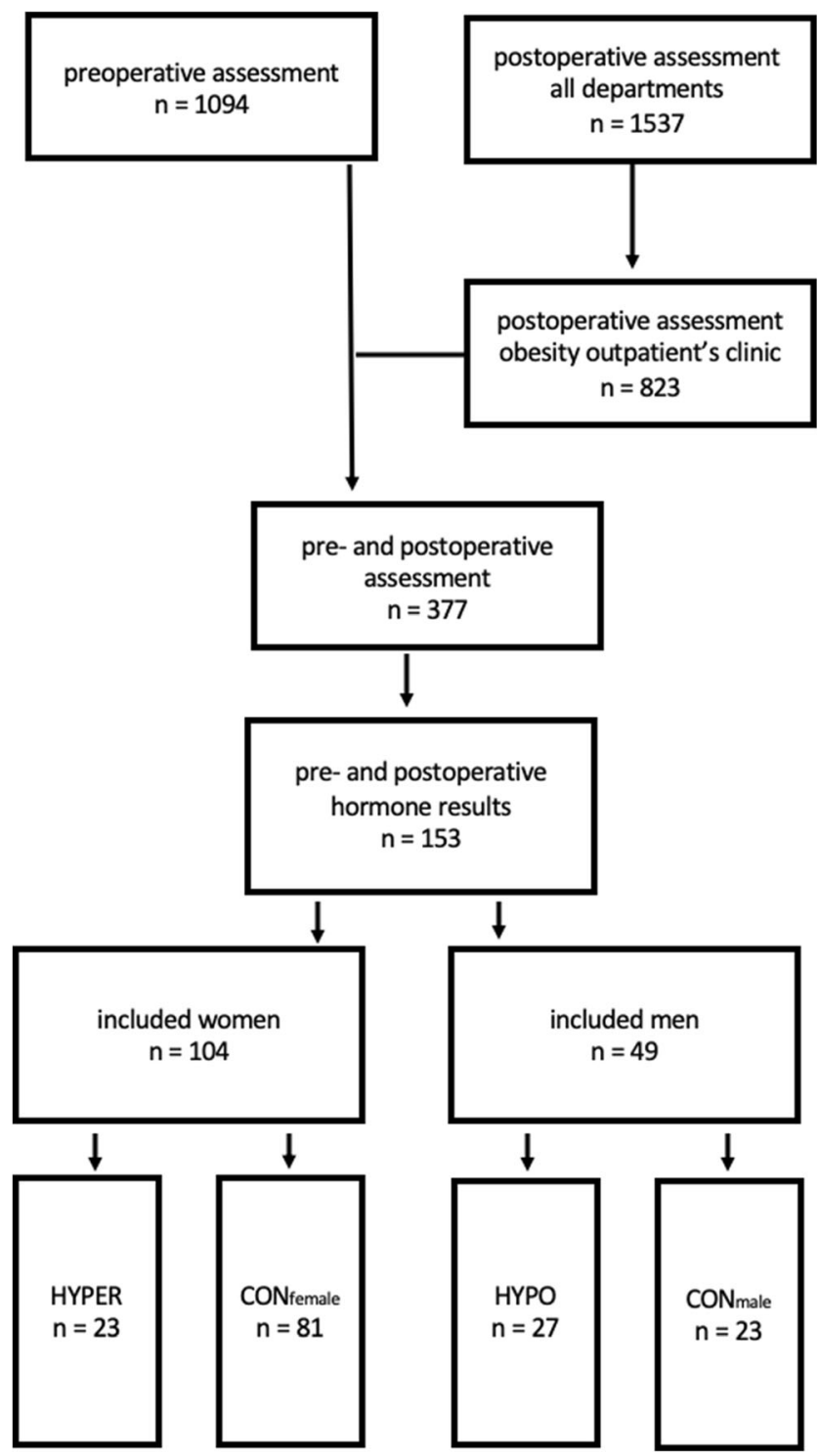

Fig. 1 Flowchart of the enrollment process; $\mathrm{CON}_{\text {male }}$, eugonadal control group; $\mathrm{HYPO}_{\text {male }}$, presence of hypogonadism before operation; $\mathrm{CON}_{\text {female, }}$ eugonadal control group; $\mathrm{HYPER}_{\text {female, }}$, presence of androgen excess before operation 
Fig. 2 Body mass index before and after bariatric surgery depending on pre-operative gonadal function in men

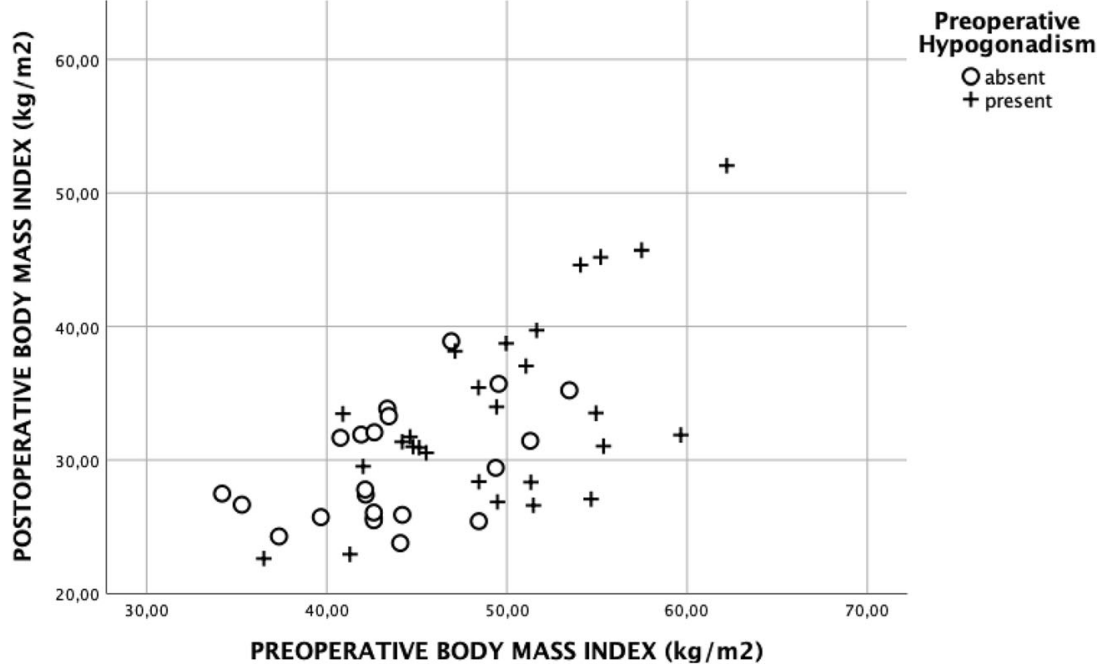

analyzed laboratory parameters included routine chemistry, parameters of glucose and lipid metabolism (glycosylated hemoglobin (HbA1c), triglycerides (TG), total cholesterol, high density cholesterol (HDL)), liver enzymes (gammaglutamyltransferase (GGT), aspartate aminotransferase (ASAT), alanine aminotransferase (ALAT)), androgens (testosterone, bioavailable testosterone, androstenedione, dehydroepiandrosterone sulfate (DHEAS)), follicle-stimulating hormone (FSH), luteinizing hormone ( $\mathrm{LH})$, and sex hormone binding globulin (SHBG).

The conditions of hypogonadism and hyperandrogenemia were defined according to assay-specific reference values (www.kimcl.at). Hypogonadism in men was defined as a testosterone level less than $1.9 \mathrm{ng} / \mathrm{mL}$ in men aged 50 years or more and testosterone levels less than $2.5 \mathrm{ng} / \mathrm{mL}$ in men aged less than 50 years. To define hyperandrogenemia in women, first FSH levels were used to biochemically define pre- and postmenopausal hormone status. FSH levels greater than $26 \mathrm{mIU} /$ $\mathrm{mL}$ were defined as post-menopausal status. In addition, agedependent values of DHEAS, testosterone, and androstenedione were used for further division. Testosterone levels greater than 0 . $41 \mathrm{ng} / \mathrm{mL}$ in women aged 50 years or more, as well as testosterone levels greater than $0.48 \mathrm{ng} / \mathrm{mL}$ in women less than 50 years of age, were considered to be hyperandrogenemia. DHEAS levels greater than $3.4 \mu \mathrm{g} / \mathrm{mL}$ in women 45 years of age or younger, as well as DHEAS levels greater than $2.6 \mu \mathrm{g} / \mathrm{mL}$ in women older than 45 years, were considered as hyperandrogenemia. Cut-off values for androstenedione levels depended on pre- or post-menopausal hormone status. Hyperandrogenemia was defined in post-menopausal women at levels greater than $2.1 \mathrm{ng} / \mathrm{mL}$ and in pre-menopausal women at levels greater than $3.4 \mathrm{ng} / \mathrm{mL}$. Hyperandrogenemia was defined by increased concentrations of at least one parameter (DHEAS, testosterone, or androstenedione).

Cushing disease was excluded in all patients in routine care by adequate suppression of morning cortisol concentrations during a 1-mg dexamethasone suppression test preoperatively performed in routine care.

The men were grouped according to the presence of hypogonadism before bariatric surgery in $\mathrm{HYPO}_{\text {male }}$
Fig. 3 Body mass index before and after bariatric surgery depending on pre-operative gonadal function in women

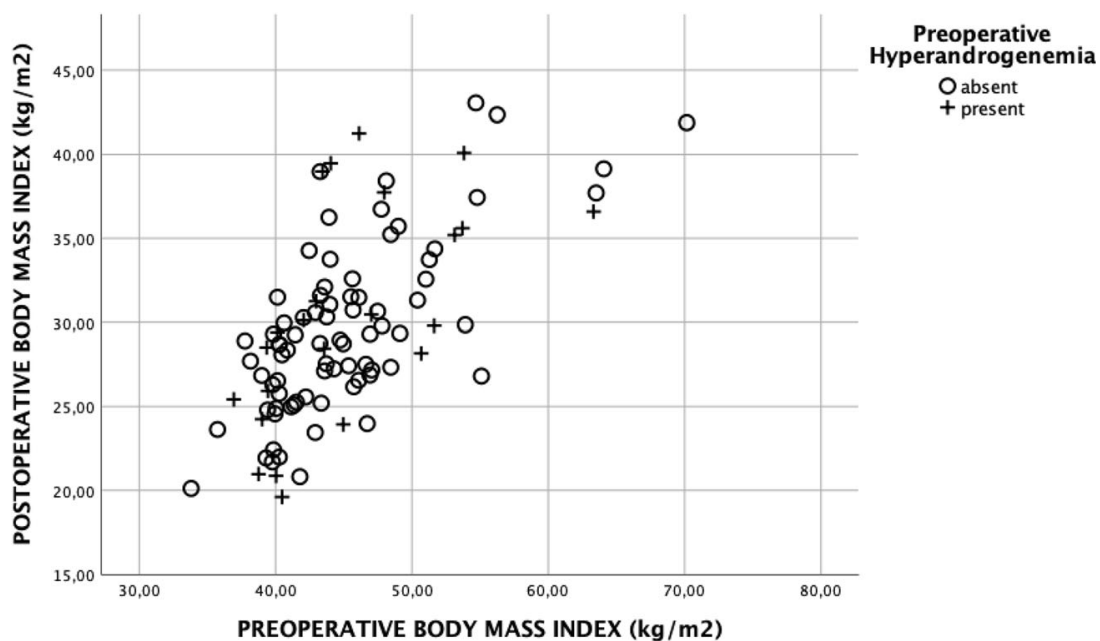


(presence of hypogonadism) or $\mathrm{CON}_{\text {male }}$ (eugonadal controls). The women were grouped according to the presence of androgen excess before surgery in HYPER female (presence of hyperandrogenemia) or $\mathrm{CON}_{\text {female }}$ (eugonadal controls). All laboratory parameters were assessed by using routine laboratory methods (www.kimcl.at).

\section{Statistical Analysis}

The statistical analysis was performed using SPSS (IBM, version 25) and Microsoft Excel (Microsoft, 2018). The normal distribution was checked by data visualization. Student $t$ tests (paired and unpaired) were used to compare data pre- and post-operatively and to compare the two groups. The data were analyzed using exploratory statistical analysis. The data are given as means \pm standard deviations. The statistical significance level was set at $p<0.05$.

\section{Results}

In total, 153 patients were included. Hypogonadism was present in 27 of 49 men pre-operatively and normalized in 25 patients (93\%) after a median follow-up period of $1.49 \pm$ 0.9 years. Body weight and BMI were significantly higher in $\mathrm{HYPO}_{\text {male }}$ before bariatric surgery (see Table 1). No significant differences in glucose metabolism, triglycerides, and cholesterol were observed pre-operatively. At the last follow-up visit, weight loss and reduction in BMI were comparable between $\mathrm{HYPO}_{\text {male }}$ and $\mathrm{CON}_{\text {male }}$. Despite normalization of preoperative hypogonadism in 25 of 27 patients, levels of testosterone were still significantly higher in $\mathrm{CON}_{\text {male }}$. Favorable changes in surrogate markers of glucose metabolism and lipid metabolism were observed in both groups, $\mathrm{HYPO}_{\text {male }}$ and $\mathrm{CON}_{\text {male }}$. These changes were not significantly different between the groups. Pre- and post-operative data are provided in detail in Table 1. Roux-en-Y gastric bypass (RYGB) was the most frequently performed surgical procedure in men (51\%) followed by one anastomosis gastric bypass (OAGB) (29\%). Sleeve gastrectomy and single anastomosis duodeno-ileal switch (SADIS) was performed in $14 \%$ and $6 \%$, respectively. The frequencies of different bariatric procedures were comparable between $\mathrm{CON}_{\text {male }}$ and $\mathrm{HYPO}_{\text {male }}$ (see Table 1).

In total, 104 women were included in the study, of which 23 fulfilled the criteria of hyperandrogenemia pre-operatively. Androgen excess was resolved in $14(61 \%)$ patients at the follow-up. Body weight and BMI were not significantly different between HYPER female and $\mathrm{CON}_{\text {female }}$ before surgery (see Table 2). Besides with increased androgen levels, there were no significant differences pre-operatively in glucose metabolism and lipid metabolism between these two groups. Weight loss and reduction in BMI were similar in
HYPER $_{\text {female }}$ and $\mathrm{CON}_{\text {female }}$ at the last follow-up. Hyperandrogenemia was still present in nine (39\%) women. At the follow-up, the levels of testosterone, DHEAS, and androstenedione in HYPER $_{\text {female }}$ were still significantly higher but within the normal range. In both groups at follow-up, favorable changes in lipid metabolism and glucose metabolism were observed compared with baseline (see Table 2). In women, OAGB was performed in $59 \%$, followed by RYGB in $27 \%$. Moreover, sleeve gastrectomy and SADIS was performed in $13 \%$ and $2 \%$, respectively. The frequencies of different surgical procedures were comparable between $\mathrm{CON}_{\text {female }}$ and HYPER female (see Table 2).

\section{Discussion}

Our study demonstrates that (i) alterations in androgen levels are frequently observed in bariatric surgery candidates and that (ii) the presence of hypogonadism in men and androgen excess in women has no impact on weight loss and the favorable changes in post-operative glucose and lipid metabolism. This study adds to the knowledge of sex-specific changes in androgen levels following bariatric surgery for both women and men.

Obesity has a crucial impact on testosterone levels in both sexes, which might be explained by alterations in the synthesis of SHBG. Sex hormones are lipophilic and therefore bind to SHBG in the blood. Decreased SHBG synthesis in the liver is found in men and women with obesity. A decrease in SHBG levels is temporarily associated with an increase in free testosterone. In men, testosterone is then converted into estradiol by the aromatase located in the adipose tissue. Estradiol itself has a suppressing effect on gonadotropins and therefore results in decreased testosterone levels [17, 20, 21]. Other mechanisms such as alterations in central insulin and leptin signaling might also have an impact on GnRH secretion [22]. Depending on the severity of obesity, different pathophysiological mechanisms are suggested to lower testosterone in men. Decreased SHBG is the predominant factor in men with mild obesity, whereas suppression of the hypothalamic-pituitary-testicular axis by inflammatory cytokines and leptin might be mainly responsible for low testosterone in men with severe obesity [23]. In our analysis, we observed a significantly higher BMI and a significantly lower SHBG in men with low testosterone levels before bariatric surgery compared with those with normal testosterone levels.

The pre-operative prevalence of hypogonadism in our study was $55 \%$, which is comparable with previous reports [24]. Of note, in the follow-up after bariatric surgery, testosterone levels increased significantly and hypogonadism resolved in nearly all men $(25 / 27,93 \%)$. Despite differences in absolute body weight, the amount of weight reduction between $\mathrm{HYPO}_{\text {male }}$ and $\mathrm{CON}_{\text {male }}$ was comparable. Based on 
Table 1 Anthropometric data and laboratory parameters in men in the study

\begin{tabular}{|c|c|c|c|c|}
\hline & \multicolumn{2}{|l|}{ Pre-operative } & \multicolumn{2}{|l|}{ Follow-up } \\
\hline & $\mathrm{CON}_{\text {male }}$ & $\mathrm{HYPO}_{\text {male }}$ & $\mathrm{CON}_{\text {male }}$ & $\mathrm{HYPO}_{\text {male }}$ \\
\hline$N$ & 22 & 27 & 22 & 27 \\
\hline Follow-up (months) & & & $14.8 \pm 9.2$ & $20.5 \pm 11.6$ \\
\hline Age (years) & $41 \pm 11$ & $43 \pm 11$ & $42 \pm 11$ & $45 \pm 11$ \\
\hline Body weight (kg) & $138.7 \pm 20.5$ & $154.3 \pm 20.7^{\#}$ & $93.5 \pm 17.6^{*}$ & $104.9 \pm 22.9 *$ \\
\hline BMI $\left(\mathrm{kg} / \mathrm{m}^{2}\right)$ & $43.6 \pm 4.8$ & $49.5 \pm 6.1^{\#}$ & $29.3 \pm 4.3^{*}$ & $33.6 \pm 7.2^{\# *}$ \\
\hline Weight loss (kg) & - & - & $-45.2 \pm 14.8$ & $-49.4 \pm 18.5$ \\
\hline BMI reduction & - & - & $-14.2 \pm 4.7$ & $-15.9 \pm 5.9$ \\
\hline RYGB $(\% ; n)$ & $50 \% ; 11$ & $52 \% ; 14$ & - & - \\
\hline OAGB $(\% ; n)$ & $27 \% ; 6$ & $30 \% ; 8$ & - & - \\
\hline Sleeve $(\% ; n)$ & $18 \% ; 4$ & $11 \% ; 3$ & - & - \\
\hline SADIS $(\% ; n)$ & $5 \% ; 1$ & $7 \% ; 2$ & - & - \\
\hline ASAT (U/L) & $33 \pm 19$ & $29 \pm 10$ & $31 \pm 18$ & $26 \pm 8$ \\
\hline $\operatorname{ALAT}(\mathrm{U} / \mathrm{L})$ & $56 \pm 40$ & $46 \pm 18$ & $39 \pm 24$ & $34 \pm 19^{*}$ \\
\hline GGT (U/L) & $53 \pm 49$ & $46 \pm 25$ & $38 \pm 29$ & $26 \pm 15^{*}$ \\
\hline $\mathrm{TG}(\mathrm{mg} / \mathrm{dL})$ & $166 \pm 80$ & $211 \pm 170$ & $94 \pm 36^{*}$ & $102 \pm 54^{*}$ \\
\hline Total cholesterol (mg/dL) & $183 \pm 42$ & $186 \pm 47$ & $145 \pm 26^{*}$ & $152 \pm 37^{*}$ \\
\hline HDL cholesterol (mg/dL) & $40 \pm 10$ & $41 \pm 10$ & $48 \pm 15^{*}$ & $52 \pm 15^{*}$ \\
\hline $\operatorname{HbA1c}(\%)$ & $6.0 \pm 1.2$ & $6.1 \pm 1.1$ & $5.1 \pm 0.3^{*}$ & $5.10 \pm 0.5^{*}$ \\
\hline Testosterone (ng/mL) & $3.47 \pm 1.09^{\#}$ & $1.66 \pm 0.40^{\#}$ & $6.92 \pm 2.47 *$ & $4.60 \pm 1.84^{\# *}$ \\
\hline Bioavailable testosterone $(\mathrm{ng} / \mathrm{mL})$ & $1.68 \pm 0.50^{\#}$ & $0.97 \pm 0.30^{\#}$ & $2.15 \pm 0.57 *$ & $1.71 \pm 0.49^{\# *}$ \\
\hline DHEAS $(\mu \mathrm{g} / \mathrm{mL})$ & $2.28 \pm 1.37$ & $2.34 \pm 1.23$ & $1.87 \pm 1.16^{*}$ & $2.67 \pm 1.66$ \\
\hline Androstenedione (ng/mL) & $1.94 \pm 0.85$ & $1.24 \pm 0.64^{\#}$ & $1.56 \pm 0.96$ & $1.61 \pm 0.84 *$ \\
\hline LH (mIU/mL) & $4.23 \pm 1.90$ & $4.34 \pm 1.60$ & $6.00 \pm 2.47^{*}$ & $5.06 \pm 2.17$ \\
\hline FSH (mIU/mL) & $4.31 \pm 2.19$ & $3.92 \pm 2.72$ & $5.49 \pm 2.42 *$ & $5.34 \pm 4.64^{*}$ \\
\hline SHBG (nmol/L) & $32.3 \pm 17.2$ & $20.5 \pm 9.8^{\#}$ & $74.5 \pm 45.9^{*}$ & $50.5 \pm 27.4^{\# *}$ \\
\hline Estradiol (pg/mL) & $38.4 \pm 13.3$ & $36.0 \pm 15.5$ & $32.5 \pm 9.9^{*}$ & $36.3 \pm 14.2$ \\
\hline
\end{tabular}

$C O N_{\text {male }}$, eugonadal control group; $H Y P O_{\text {male }}$, presence of hypogonadism before bariatric surgery; $* p<0.05$ compared with baseline; ${ }^{\#} p<0.05$ compared with $\mathrm{CON}_{\text {male }}$ these observations, one might deduce that pre-operative testosterone substitution to treat hypogonadism in men with morbid obesity is not indicated, since favorable effects on body weight and sex hormones are observed in line with weight loss.

Testosterone as such also modifies muscle and fat mass, as well as insulin sensitivity, highlighting the mutual dependency. Hypogonadism due to therapy with $\mathrm{GnRH}$ agonists in men with prostate cancer is associated with increased fat mass [25, 26], whereas testosterone treatment in hypogonadism results in improved insulin sensitivity and decreased fat mass in patients with type 2 diabetes mellitus [27]. Interestingly, there is a large variety in the impact of testosterone on glucose and lipid metabolism depending on sex. Whereas in men anabolic effects of testosterone on muscle mass exert favorable metabolic benefits, hyperandrogenemia in women is associated with a higher risk of cardiovascular disease [4, 5]. Also, fat mass increases following long-term testosterone administration in female-to-male transsexuals [28].
In women, insulin resistance might play a major role in the development of androgen excess by modulation of SHBG concentrations, as well as by direct effects on adrenal androgen secretion [16]. Increased frequencies in $\mathrm{GnRH}$ pulses leading to $\mathrm{LH}$ excess with subsequent increased androgen production in the ovaries also play a major role in the pathogenesis of hyperandrogenemia, which was reported in PCOS [29]. In addition, changes in the 17 beta hydroxysteroid dehydrogenase type 3, which converts androstenedione into testosterone in adipose tissue, might be a substantial factor contributing to hyperandrogenemia [30]. Of note, in our cohort, the presence of androgen excess was independent of body weight and BMI, probably highlighting sex-dependent differences in the pathogenesis of testosterone production.

With regard to pre-operative sex hormone status in women, the prevalence of hyperandrogenemia was $22 \%$. Of note, in contrast to men, BMI did not differ between HYPER $_{\text {female }}$ and $\mathrm{CON}_{\text {female }}$ In addition, all markers of hyperandrogenemia 
Table 2 Anthropometric data and laboratory parameters in all included women

\begin{tabular}{|c|c|c|c|c|}
\hline & \multicolumn{2}{|l|}{ Pre-operative } & \multicolumn{2}{|l|}{ Follow-up } \\
\hline & $\mathrm{CON}_{\text {female }}$ & HYPER $_{\text {female }}$ & $\mathrm{CON}_{\text {female }}$ & HYPER $_{\text {female }}$ \\
\hline$n$ & 81 & 23 & 81 & 23 \\
\hline Follow-up (months) & & & $20.6 \pm 11.9$ & $14.3 \pm 8.6^{\#}$ \\
\hline Age (years) & $40 \pm 11$ & $35 \pm 10$ & $42 \pm 11$ & $36 \pm 10$ \\
\hline Body weight (kg) & $119.7 \pm 20.1$ & $123.2 \pm 23.6$ & $79.3 \pm 14.4^{*}$ & $82.9 \pm 19.5^{*}$ \\
\hline BMI $\left(\mathrm{kg} / \mathrm{m}^{2}\right)$ & $44.4 \pm 7.1$ & $45.3 \pm 6.5$ & $29.4 \pm 5.0 *$ & $30.5 \pm 6.6^{*}$ \\
\hline Weight loss (kg) & & & $-40.4 \pm 14.5$ & $-40.4 \pm 17.1$ \\
\hline BMI reduction & & & $-15.0 \pm 5.3$ & $-14.8 \pm 5.9$ \\
\hline RYGB $(\% ; n)$ & $28 \% ; 23$ & $22 \% ; 5$ & - & - \\
\hline OAGB $(\% ; n)$ & $61 \% ; 49$ & $52 \% ; 12$ & - & - \\
\hline Sleeve $(\% ; n)$ & $10 \% ; 8$ & $22 \% ; 5$ & - & - \\
\hline SADIS $(\% ; n)$ & $1 \% ; 1$ & $4 \% ; 1$ & - & - \\
\hline ASAT (U/L) & $25 \pm 12$ & $25 \pm 13$ & $24 \pm 8$ & $22 \pm 5$ \\
\hline ALAT (U/L) & $33 \pm 20$ & $32 \pm 18$ & $29 \pm 12 *$ & $25 \pm 11$ \\
\hline GGT (U/L) & $32 \pm 25$ & $29 \pm 18$ & $17 \pm 16^{*}$ & $15 \pm 9 *$ \\
\hline $\mathrm{TG}(\mathrm{mg} / \mathrm{dL})$ & $137 \pm 72$ & $149 \pm 60$ & $90 \pm 42 *$ & $105 \pm 43^{*}$ \\
\hline Total cholesterol (mg/dL) & $182 \pm 39$ & $185 \pm 40$ & $161 \pm 26^{*}$ & $159 \pm 33^{*}$ \\
\hline HDL cholesterol (mg/dL) & $49 \pm 13$ & $45 \pm 12$ & $59 \pm 14^{*}$ & $51 \pm 12^{\# *}$ \\
\hline HbA1c $(\%)$ & $5.7 \pm 0.8$ & $5.8 \pm 0.7$ & $5.1 \pm 0.4^{*}$ & $5.3 \pm 0.4^{*}$ \\
\hline Testosterone (ng/mL) & $0.23 \pm 0.11$ & $0.56 \pm 0.18^{\#}$ & $0.19 \pm 0.12 *$ & $0.39 \pm 0.18^{\# *}$ \\
\hline Bioavailable testosterone $(\mathrm{ng} / \mathrm{mL})$ & $0.09 \pm 0.06$ & $0.23 \pm 0.10^{\#}$ & $0.04 \pm 0.04 *$ & $0.08 \pm 0.06^{\# *}$ \\
\hline DHEAS $(\mu \mathrm{g} / \mathrm{mL})$ & $1.37 \pm 0.66$ & $2.97 \pm 1.12^{\#}$ & $1.16 \pm 0.59^{*}$ & $2.32 \pm 1.16^{\# *}$ \\
\hline Androstenedione $(\mathrm{ng} / \mathrm{mL})$ & $1.24 \pm 0.67$ & $2.77 \pm 1.19^{\#}$ & $1.14 \pm 0.61$ & $2.16 \pm 0.98^{\#}$ \\
\hline $\mathrm{LH}(\mathrm{mIU} / \mathrm{mL})$ & $11.52 \pm 10.97$ & $10.71 \pm 9.30$ & $14.19 \pm 14.17 *$ & $14.36 \pm 16.37$ \\
\hline FSH (mIU/mL) & $13.02 \pm 16.19$ & $10.03 \pm 12.58$ & $20.33 \pm 25.30^{*}$ & $17.30 \pm 25.55$ \\
\hline SHBG (nmol/L) & $48.9 \pm 39.1$ & $44.1 \pm 38.0$ & $103.5 \pm 51.1 *$ & $112.2 \pm 66.5^{*}$ \\
\hline Estradiol (pg/mL) & $64.7 \pm 66.3$ & $72.0 \pm 61.6$ & $106.4 \pm 174.8^{*}$ & $414.5 \pm 1561.3$ \\
\hline
\end{tabular}

$C O N_{\text {female }}$, eugonadal control group; $H Y P E R_{\text {female }}$, presence of androgen excess before bariatric surgery; ${ }^{*} p<0.05$ compared with baseline; ${ }^{*} p<0.05$ compared with $\mathrm{CON}_{\text {female }}$ (e.g., testosterone, DHEAS, and androstenedione) were substantially decreased in both groups following bariatric surgery, but still significantly higher in the HYPER female $_{\text {group. }}$ Hyperandrogenemia was reversed by bariatric surgery in $61 \%$ of women. This decrease in androgen levels observed in our study might partly explain previously published increased fertility rates in women following weight loss after bariatric surgery [31].

The major limitation of our study is the retrospective study design with all its known disadvantages. In addition, the follow-up time between the groups was slightly different. However, the estimated influence on weight loss might not be substantial, as it was shown that the majority of weight loss takes place within the first year after bariatric surgery $[32,33]$. The sample size is relatively small, which is in part explained by the limited availability of a total hormone status before and after surgery. Moreover, the number of women included in this study was twice the number of men, which is line with literature and daily clinical practice, since the majority of bariatric surgery candidates are women [34]. The cause of androgen excess in women could not be defined, and no detailed information on menstrual cycle or oligomenorrhea was available in patients' records. Based on the literature, PCOS might have been the most common differential diagnosis, with an estimated prevalence of about $30 \%$ based on previous reports [9]. However, at least Cushing syndrome was excluded by the 1-mg dexamethasone suppression test pre-operatively in all patients. In addition, detailed information on medication potentially interfering with sex hormone levels is missing. Furthermore, insulin levels were not available in most of the patients; thus, investigating the effects of improved insulin sensitivity on androgen concentrations is not possible in our cohort. With regard to differences in bariatric procedures, RYGB was most frequently performed in men, whereas OAGB was more prevalent in women. However, surgical techniques were comparable between $\mathrm{HYPO}_{\text {male }}$ and 
$\mathrm{CON}_{\text {male }}$, as well as between $\mathrm{HYPER}_{\text {female }}$ and $\mathrm{CON}_{\text {female }}$. Differences in surgery procedures between men and women therefore do not affect our data, since sex-specific analysis of post-surgical outcome was performed. Further large, prospective studies are warranted to prove the impact of gonadal function on weight loss and vice versa following bariatric surgery.

Taken together, our results suggest that bariatric surgery is a very effective way to reverse obesity-associated hypogonadism in men. In women, androgen excess is observed frequently and independently of pre-operative BMI. Despite decreased androgen concentrations following bariatric surgery, remission rates of hyperandrogenemia are lower compared with men. However, hypogonadism and androgen excess have no impact on postsurgical improvements in body weight and glucose and lipid metabolism in both sexes.

Funding Information Open access funding provided by Medical University of Vienna.

\section{Compliance with Ethical Standards}

Conflict of Interest The authors declare that they have no conflict of interest.

Ethical Approval All procedures performed in this study involving human participants were in accordance with the ethical standards of the institutional and/or national research committee and with the 1964 Helsinki Declaration and its later amendments, or comparable ethical standards.

Informed Consent For this type of study, formal consent is not required. However, all patients agreed to data collection for our registry.

Disclosure Summary The authors have nothing to declare.

Open Access This article is licensed under a Creative Commons Attribution 4.0 International License, which permits use, sharing, adaptation, distribution and reproduction in any medium or format, as long as you give appropriate credit to the original author(s) and the source, provide a link to the Creative Commons licence, and indicate if changes were made. The images or other third party material in this article are included in the article's Creative Commons licence, unless indicated otherwise in a credit line to the material. If material is not included in the article's Creative Commons licence and your intended use is not permitted by statutory regulation or exceeds the permitted use, you will need to obtain permission directly from the copyright holder. To view a copy of this licence, visit http://creativecommons.org/licenses/by/4.0/.

\section{References}

1. Inge TH, Courcoulas AP, Jenkins TM, et al. Five-year outcomes of gastric bypass in adolescents as compared with adults. N Engl J Med. 2019;380:2136-45.

2. Adams TD, Davidson LE, Litwin SE, et al. Weight and metabolic outcomes 12 years after gastric bypass. N Engl J Med. 2017;377: $1143-55$.
3. Aminian A, Zajichek A, Arterburn DE, et al. Association of metabolic surgery with major adverse cardiovascular outcomes in patients with type 2 diabetes and obesity. JAMA. 2019;322:1271.

4. Schiffer L, Kempegowda P, Arlt W, et al. Mechanisms in endocrinology: the sexually dimorphic role of androgens in human metabolic disease. Eur J Endocrinol. 2017;177:R125-43.

5. Bianchi VE, Locatelli V. Testosterone a key factor in gender related metabolic syndrome. Obes Rev. 2018;19:557-75.

6. Zarotsky V, Huang M-Y, Carman W, et al. Systematic literature review of the risk factors, comorbidities, and consequences of hypogonadism in men. Andrology. 2014;2:819-34.

7. Corona G, Rastrelli G, Monami M, et al. Hypogonadism as a risk factor for cardiovascular mortality in men: a meta-analytic study. Eur J Endocrinol. 2011;165:687-701.

8. Rigon FA, Ronsoni MF, Hohl A, et al. Effects of bariatric surgery in male obesity-associated hypogonadism. Obes Surg. 2019;29:211525 .

9. Escobar-Morreale HF, Santacruz E, Luque-Ramirez M, et al. Prevalence of "obesity-associated gonadal dysfunction" in severely obese men and women and its resolution after bariatric surgery: a systematic review and meta-analysis. Hum Reprod Update. 2017;23:390-408.

10. Samavat J, Facchiano E, Lucchese M, Forti G, Mannucci E, Maggi $\mathrm{M}$, et al. Hypogonadism as an additional indication for bariatric surgery in male morbid obesity? Eur J Endocrinol. England; 2014;171:555-560.

11. Traish AM, Haider A, Doros G, Saad F. Long-term testosterone therapy in hypogonadal men ameliorates elements of the metabolic syndrome: an observational, long-term registry study. Int J Clin Pract. 2013/10/15. BlackWell Publishing Ltd; 2014;68:314-29.

12. Skinner JW, Otzel DM, Bowser A, et al. Muscular responses to testosterone replacement vary by administration route: a systematic review and meta-analysis. J Cachexia Sarcopenia Muscle. 2018;9: $465-81$.

13. Alvarez-Blasco F, Botella-Carretero JI, San Millán JL, et al. Prevalence and characteristics of the polycystic ovary syndrome in overweight and obese women. Arch Intern Med. 2006;166: 2081-6.

14. Valderhaug TG, Hertel JK, Nordstrand N, Dale PO, Hofsø D, Hjelmesæth J. The association between hyperandrogenemia and the metabolic syndrome in morbidly obese women. Diabetol Metab Syndr. BioMed Central; 2015;7:46.

15. Martínez-Bermejo E, Luque-Ramírez M, Escobar-Morreale HF. Obesity and the polycystic ovary syndrome. Minerva Endocrinol. 2007;32:129-40.

16. Wang J, Wu D, Guo H, Li M. Hyperandrogenemia and insulin resistance: the chief culprit of polycystic ovary syndrome. Life Sci. 2019/10/08. Netherlands; 2019;236:116940.

17. Yasmin E, Balen AH, Barth JH. The association of body mass index and biochemical hyperandrogenaemia in women with and without polycystic ovary syndrome. Eur J Obstet Gynecol Reprod Biol. 2013;166:173-7.

18. Pasquali R. Obesity and androgens: facts and perspectives. Fertil Steril. 2006;85:1319-40.

19. Li Y-J, Han Y, He B. Effects of bariatric surgery on obese polycystic ovary syndrome: a systematic review and meta-analysis. Surg Obes Relat Dis. 2019;15:942-50.

20. Hofstra J, Loves S, van Wageningen B, et al. High prevalence of hypogonadotropic hypogonadism in men referred for obesity treatment. Neth J Med. 2008;66:103-9.

21. Pivonello R, Menafra D, Riccio E, et al. Metabolic disorders and male hypogonadotropic hypogonadism. Front Endocrinol. 2019; 10:345.

22. Dhindsa S, Ghanim H, Batra M, et al. Hypogonadotropic hypogonadism in men with diabesity. Diabetes Care. 2018;41: 1516-25. 
23. Grossmann M. Hypogonadism and male obesity: focus on unresolved questions. Clin Endocrinol. 2018;89:11-21.

24. Calderón B, Gómez-Martín JM, Vega-Piñero B, et al. Prevalence of male secondary hypogonadism in moderate to severe obesity and its relationship with insulin resistance and excess body weight. Andrology. 2015;4:62-7.

25. Smith MR, Lee H, McGovern F, et al. Metabolic changes during gonadotropin-releasing hormone agonist therapy for prostate cancer: differences from the classic metabolic syndrome. Cancer. 2008;112:2188-94.

26. Smith MR, Finkelstein JS, McGovern FJ, et al. Changes in body composition during androgen deprivation therapy for prostate cancer. J Clin Endocrinol Metab. 2002;87:599-603.

27. Dhindsa S, Ghanim H, Batra M, et al. Insulin resistance and inflammation in hypogonadotropic hypogonadism and their reduction after testosterone replacement in men with type 2 diabetes. Diabetes Care. 2016;39:82-91.

28. Elbers JM, Asscheman H, Seidell JC, et al. Long-term testosterone administration increases visceral fat in female to male transsexuals. J Clin Endocrinol Metab. 1997;82:2044-7.

29. McCartney CR, Marshall JC. Clinical practice. Polycystic ovary syndrome. N Engl J Med. 2016;375:54-64.

30. Corbould AM, Bawden MJ, Lavranos TC, et al. The effect of obesity on the ratio of type 3 17beta-hydroxysteroid dehydrogenase mRNA to cytochrome P450 aromatase mRNA in subcutaneous abdominal and intra-abdominal adipose tissue of women. Int J Obes Relat Metab Disord. 2002;26:165-75.

31. Butterworth J, Deguara J, Borg C-M. Bariatric surgery, polycystic ovary syndrome, and infertility. J Obes. 2016/11/14. Hindawi Publishing Corporation; 2016;2016:1871594.

32. Worm D, Madsbad S, Kristiansen VB, et al. Changes in hematology and calcium metabolism after gastric bypass surgery-a 2-year follow-up study. Obes Surg. 2015;25:1647-52.

33. Guerreiro V, Neves JS, Salazar D, et al. Long-term weight loss and metabolic syndrome remission after bariatric surgery: the effect of sex, age, metabolic parameters and surgical technique - a 4-year follow-up study. Obes Facts. 2019:1-14

34. Welbourn R, Hollyman M, Kinsman R, et al. Bariatric surgery worldwide: baseline demographic description and one-year outcomes from the fourth IFSO Global Registry Report 2018. Obes Surg. 2019;29:782-95.

Publisher's Note Springer Nature remains neutral with regard to jurisdictional claims in published maps and institutional affiliations. 